\title{
Chapter 4 \\ Integrating a Solar PV System \\ with a Household Based Backup \\ Generator for Hybrid Swarm \\ Electrification: A Case Study of Nigeria
}

\author{
Rolex Muceka, Tonny Kukeera, Yunus Alokore, Kebir Noara \\ and Sebastian Groh
}

\begin{abstract}
Today most of the electrification grids in sub-Saharan Africa (SSA) are found in urban areas. However, these grids experience erratic and frequent power outages for long hours, on average $4.6 \mathrm{~h}$ in a day. Due to this problem, many of the African population rely on cheaper but unclean options like backup diesel/petrol generators for lighting, phone charging and other electrical appliances. In Nigeria, millions of people own power generators. These generators are not only noisy but the fuel they use is also costly and result into emissions that pollute the environment. In order to optimize fuel consumption and gradually reduce use of backup generators while increasing share of renewables, a strategy is proposed in this paper to interconnect the existing backup infrastructure to form a bottom-up swarm electrification grid with step by step integration of alternative storages and renewable energy sources. In the swarm-grid excess energy can be generated, sold among grid participants and even at later stage to the national grid. This study
\end{abstract}

R. Muceka $(\bowtie) \cdot$ T. Kukeera

Pan African University Institute of Water and Energy Sciences

(Including Climate Change), B.P. 119, Pôle Chetouane, Tlemcen 13000, Algeria

e-mail: mckrolex@gmail.com

T. Kukeera

e-mail: tonnykukeera@gmail.com

Y. Alokore

Viva Energy International Ltd., P.O. Box 460, Arua, Uganda

e-mail: y.alokore@vivaenergyinternational.com

URL: http://www.vivaenergyinternational.com/

K. Noara

MicroEnergy International, Potsdamer Str. 143, 10783 Berlin, Germany

e-mail: noara.kebir@microenergy-international.com

S. Groh

School of Business and Economics, North South University,

Plot 15, Block B, Bashundhara, Dhaka 1229D, Bangladesh

e-mail: sgroh85@gmail.com

(C) The Author(s) 2018

M. Mpholo et al. (eds.), Africa-EU Renewable Energy Research and Innovation Symposium 2018 (RERIS 2018), Springer Proceedings in Energy,

https://doi.org/10.1007/978-3-319-93438-9_4 
focused on a swarm grid hybrid node consisting of a solar PV system integrated with the existing individual backup generators for households and retail shop end users. The hybrid system designed was found to be a suitable system with fuel savings of $39 \%$, excess energy of $27 \%$ and reduced cost of backup electricity by $34 \%$ for the household end user. For the retail shop end user, the hybrid system was found to be a suitable system with a fuel cost saving of 53\%, excess energy generation of $28 \%$ and reduced cost of backup electricity by $45 \%$. The study showed that integration of a solar PV system has a high potential to reduce fuel costs for backup generator end users and presents a great opportunity for hybrid swarm electrification approach.

Keywords National grid · Stand-alone system - Swarm grid • Renewable energy Excess energy

\subsection{Introduction}

Sub-Saharan Africa (SSA), a region in Africa where most of the population without access to electricity lives. The percentage population in SSA without access to electricity was about $63 \%$ in 2014 [1]. The main source of lighting continues to be kerosene lamps, firewood and candles, especially for regions off the main grid. Furthermore, even those with access to the central main grid often suffer from unpredictable power outages for long hours, on average $4.6 \mathrm{~h}$ per day, with 17 countries exceeding the average outage duration [2]. According to World Bank's enterprise surveys, last updated in October 2016, the average number of power outages in firms, in a typical month is 8.5 [3]. Many countries experience frequent outages in SSA with the worst scenario seen in Nigeria with 32.8 outages in a month. Other countries with high cases include; the Central African Republic with 29 outages, Congo 21.5, Chad 19.6, Niger 18.5, and Burundi with 16.6 outages [2]. This has led many people in peri-urban areas and trading centres in many countries in Africa to rely on unclean options like backup diesel/petrol generators for lighting, phone charging, and other electrical appliances.

Besides being noisy and producing emissions that are harmful to the environment, backup generators use fuel which makes them costly to maintain and use in the long run. Taking a case for Nigeria; private households spend over $\$ 13.35$ million USD annually on alternate sources of energy [4]. This figure adds to over $\$ 21.8$ billion USD per year if enterprises and manufacturers are also considered [4]. For small businesses, fuel costs account for $40 \%$ of their total overheads [5].

Owing to a pressing need to protect the environment, cut down fuels costs and promote energy efficiency, as expressed in the sub-goals of the Sustainable Development Goal (SDG) 7 with its main to ensure access to affordable, reliable, sustainable, and modern energy for all, a strategy is proposed to interconnect this existing backup power infrastructure in a swarm grid and to integrate alternative storage and renewable energy generators step by step. By doing so, it is anticipated 


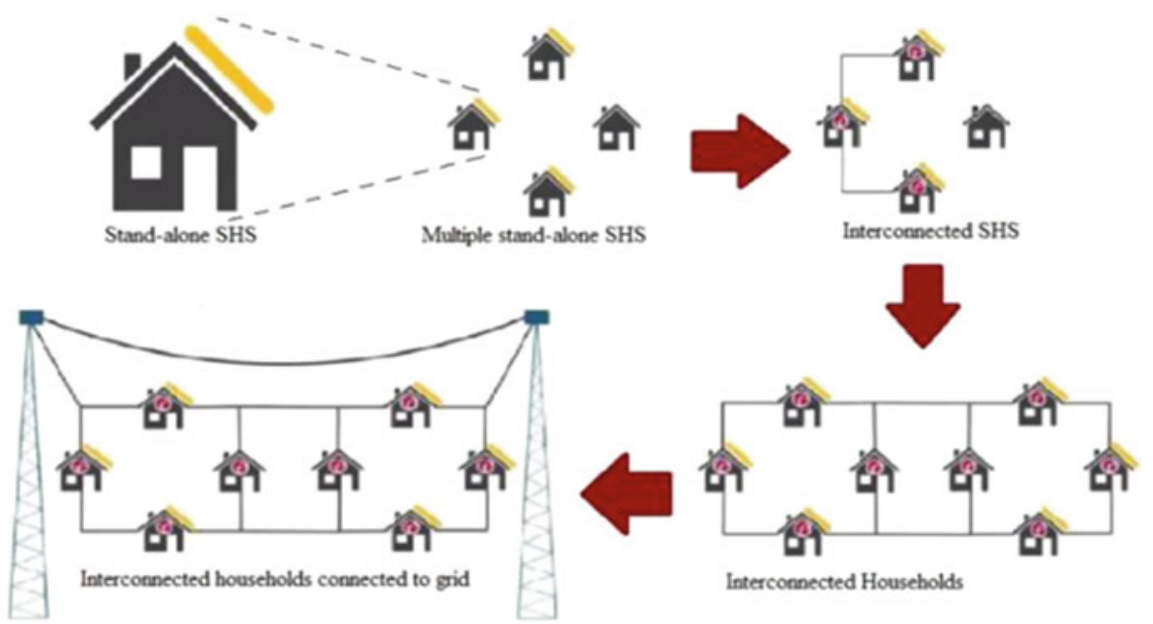

Fig. 4.1 Swarm electrification approach source [6]

that fuel consumption of backup generators could be optimized and gradually reduced, and the share of renewable energy could be increased too. The incremental development of such a grid does not require huge investments from the household or a small enterprise, but can be done using the savings realized on each step. Furthermore, a hypothesis is set up, that each generator in the swarm grid and the swarm grid as a unit can generate excess electricity which can be sold among grid participants and at a later stage even to the national grid. Figure 4.1 shows a representation of swarm electrification approach.

A swarm grid is a grid formed from interconnecting multiple households and small businesses with or without Solar Home Systems (SHS). The concept is known as Swarm Electrification (SE). This concept has been applied in Bangladesh. The end users forming the grid have the ability to share excess energy among themselves. SE allows the households and the small enterprises to become prosumers, i.e. producers and consumers at the same time. As a producer, a node can share or trade the excess energy with its neighbor or as a consumer, a node gets its unmet energy from the neighbors [6]. In a swarm grid a node represents a consumer and/or producer end user.

This paper proposes a strategy of forming a hybrid swarm grid with more than one source of energy in the grid as a whole, and at some nodes in particular. In the following steps, the proposed strategy is described one by one:

1. Integrating an existing generator into a swarm-grid and smart electricity management unit.

- Excess energy is generated while operating a generator at an optimal point efficiency i.e. $80 \%$. 
- The energy can be shared and traded between swarm-grid participants, unlocking capital.

2. Using the capital to invest into batteries, excess energy generated from constantly operating the generators at an optimal point can be stored.

3. The electricity stored in the battery (ies) can be used instead of the generators.

- This reduces the usage hours of a generator hence prolonging its lifespan.

4. Solar PV panels or other renewable energy sources can be integrated to the swarm-grid at the nodes. They can be used as a direct source of power and for charging the batteries.

- Fuel can be saved; excess energy is generated from solar.

- More energy can be shared and traded, unlocking capital for further investment.

5. Step by step, according to the needs, such a grid can grow by adding storage and generation capacities. More users can be integrated and trade with the electricity.

6. Generation and storage capacities might not only be used for backup during power outages but also for extended periods during the day, replacing step by step the power from the grid.

7. When the swarm-grid grows large enough and produces enough excess energy, interconnection with the national grid and a feed in-option can be considered.

This type of grids can grow organically. Each step is voluntary. The economic viability of each step still needs to be proven. The schematic representation of the hybrid swarm grid is shown in Fig. 4.2.

In Nigeria, according to a survey by [7] in the states of Delta, Bayelsa and Rivers, $43 \%$ of households with grid connection use backup generators for at least $4 \mathrm{~h}$. Also $40 \%$ of the small enterprises with grid connection have less than four hours of electricity supply in a day. In a hybrid swarm grid, a prosumer can be a hybrid node (with more than one energy source at the node) and hence benefits from the merits of combined power sources. A household or small enterprise with a backup fossil-fuel generator could become such a hybrid node by integration of battery and solar PV generator as described in steps 3 and 4 above.

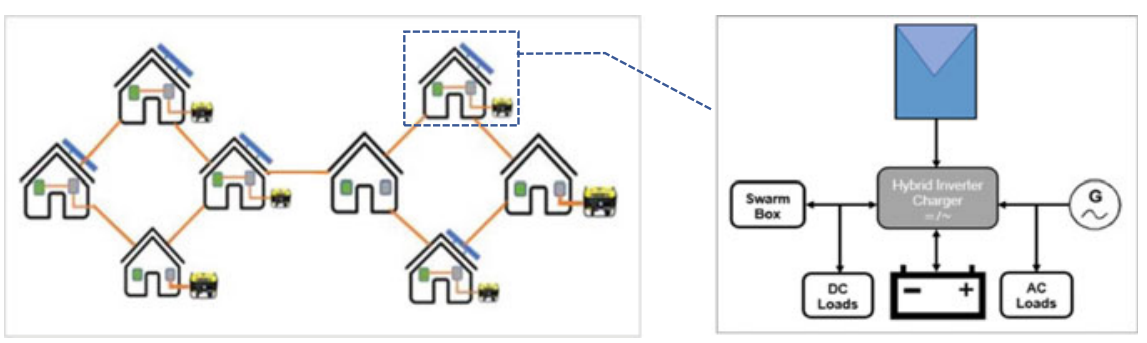

Fig. 4.2 Hybrid swarm grid and a hybrid node 
This study focusses on the hybrid node of a swarm grid. With the main objective of contributing to a hybrid swarm grid, the study aimed at designing a hybrid node by integrating a solar PV system for a potential benefit of fossil-fuel savings. The focus was also to quantify excess energy production and determine its potential for sharing in a hybrid swarm grid.

\subsection{Methodology}

The three states of Bayelsa, Delta and Rivers in Nigeria were chosen as the study areas. The solar energy potential for the study area was determined based on the solar radiation database for PV performance estimation in Europe and Africa [8]. From the literature in [9-11], load profiles were developed for the household and a small enterprise end users as shown in Figs. 4.3 and 4.4.

From the load profiles, the energy demands were estimated, the hybrid units designed controlled by the technical and economic parameters. The energy production and use for the hybrid units designed was further assessed for potential excess energy generation.

\subsubsection{Solar Energy Demand}

The daily solar energy demand is the solar energy required to charge the battery and as a direct power source in the day [12].

$$
W_{p v}=W_{p v b a t}+W_{p v d a y}
$$

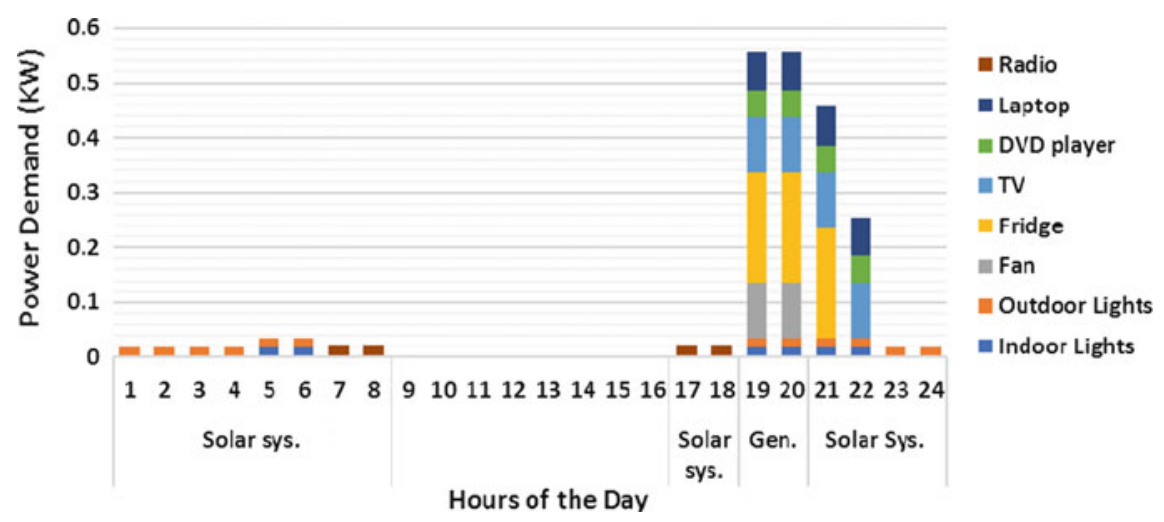

Fig. 4.3 Household end user load profile 


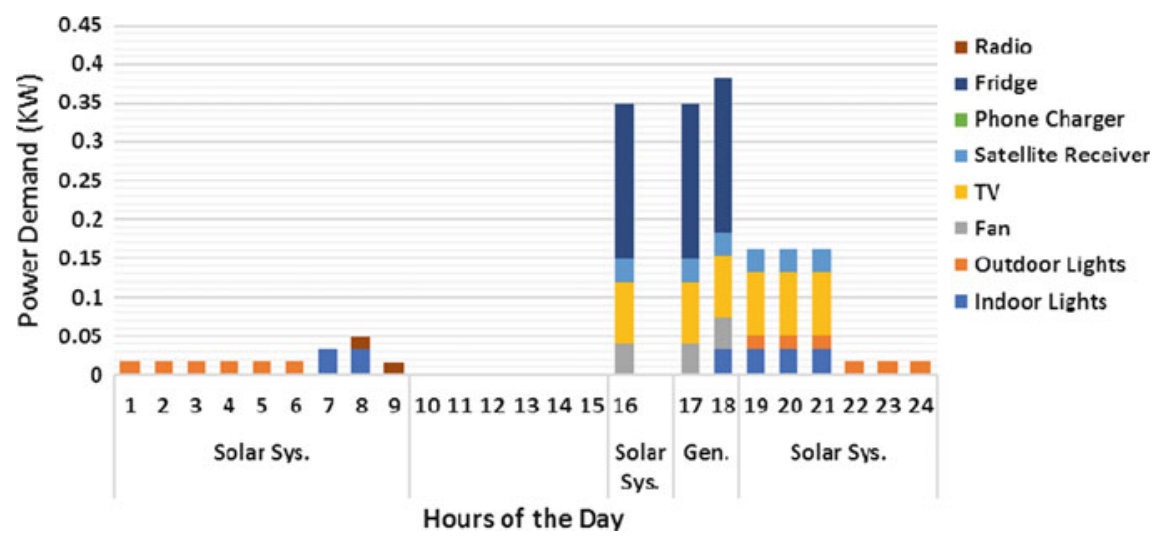

Fig. 4.4 Retail shop end user load profile

where $W_{\text {pvbat }}$ is solar energy demand to charge the battery, $W_{p v d a y}$ is solar energy demand for direct load supply during the day.

\subsubsection{Battery Storage}

The battery is considered like a pot used to store water during the day for later use at night. The method (7) [12] given below is used to size the battery storage;

$$
B_{B}=\frac{E_{b a t} \times A D}{V_{s} \times D O D \times \eta_{\text {inv }}}
$$

where $B_{B}$ is battery storage size in Ampere hours (Ah), $E_{\text {bat }}$ is energy storage demand (Wh), $A D$ is autonomous days, $V_{s}$ is system voltage, $D O D$ is depth of discharge $(60 \%), \eta_{i n v}$ is Inverter efficiency $(90 \%)$.

$$
E_{\text {bat }}=E_{\text {bat_night }}+\left(E_{d} \times 10 \%\right)
$$

where $E_{\text {bat_night }}$ is energy storage demand by loads at night, $E_{d}$ is day time load energy demand.

In this study, $10 \%$ of the day time energy demand is stored to take care of abrupt changes in solar radiation due to swift movements of clouds. 


\subsubsection{Backup Fossil-Fuel Generator}

The rated size of backup generator considered in this study is $1.0 \mathrm{~kW}$ each for the household and the small enterprise users, the size is big enough to power the peak demands in the load profiles of the users.

\subsubsection{System Solar PV Production}

The method applied for the daily estimation of the PV performance is given below [13];

$$
P_{p v}=P_{w p} \times \frac{G}{G^{\prime}} \times\left[1+\alpha_{t}\left(T_{a}-T_{r e f}\right)\right]
$$

where $P_{p v}$ is daily power output of the PV panels at a time, $P_{w p}$ is total $\mathrm{PV}$ watt peak under reference conditions, $G$ is daily solar irradiation $\left(\mathrm{W} / \mathrm{m}^{2}\right)$ at optimal angle $\left(11^{\circ}\right), G^{\prime}$ is the reference solar radiation $\left(1000 \mathrm{~W} / \mathrm{m}^{2}\right) ; T_{a}$ is the daily ambient temperature, and $T_{r e f}$ is the reference temperature $\left(25^{\circ} \mathrm{C}\right) ; \alpha_{t}$ is the PV panel temperature coefficient; for mono and poly crystalline silicon materials.

\subsubsection{Excess/Unmet Energy}

Due to the day to day changes in weather, the daily energy production from solar is not the same. On brighter days, the solar irradiations are high and hence high energy production. This energy can be more than what is needed in a day resulting in excess energy and hence is put to waste if not utilized. By performing the solar energy production and consumption analysis, excess/unmet solar energy generation is assessed on daily basis. Excess energy is the energy that could be generated if the battery had not been fully charged or if there was an extra load to be supplied. In this study, the total daily solar energy demand is assumed to be constant in a year.

$$
\text { Excess } / \text { Unmet }_{\text {Energy }}=P_{p v}-W_{p v}
$$

If Eq. (4.5) gives a positive number, it is excess energy and if a negative number, it is unmet energy. During cloudy days or in the rainy season when the unmet energy is most generated, backup fossil-fuel is used to meet the unmet energy. 


\subsubsection{Economic Analysis}

The Annualized Cost of the System (ACS) obtained from Eq. (4.6) is the cost of the system spread or discounted yearly over the whole system lifetime [14].

$$
A C S=A C C+A O M+A R C+A F C
$$

where ACC is the annualized capital cost, AOM is the annualized operation and maintenance cost, ARC is the annualized replacement cost, AFC is the annualized fuel consumption cost.

$$
\begin{array}{r}
A C C=C_{c} \times C R F\left(i^{\prime}, n\right) \\
C R F=\frac{i^{\prime}\left(1+i^{\prime}\right)^{n}}{\left(1+i^{\prime}\right)^{n}-1} \\
i^{\prime}=\frac{i-f}{1+f}
\end{array}
$$

where $C_{c}$ is the capital cost (\$ USD), $C R F$ is the capital recovery factor, $n$ is the lifetime of the component in years, $f$ is the inflation rate, $i$ is the nominal interest rate.

$$
\begin{array}{r}
A R C=C_{\text {rep }} \times K-A S V \\
K=N_{\text {rep }} \times \operatorname{SFF}\left(i^{\prime}, n\right) \\
N_{\text {rep }}=\frac{y}{n}-1 \text { if } y \text { is divisible by } n \\
N_{\text {rep }}=I N T\left[\frac{y}{n}\right] \text { if } y \text { is not divisible by } n \\
S F F=\frac{i^{\prime}}{\left(1+i^{\prime}\right)^{n}-1}
\end{array}
$$

where $y$ is the lifetime of the system, $N_{\text {rep }}$ is number of replacement, $A S V$ is annualized salvage value, $S F F$ is sinking fund factor.

$$
A S V=S \times S F F\left(i^{\prime}, y\right)
$$

If $y$ is not divisible by $n$, the salvage value, $S$ of the replaceable component is determined as in [9], with $R_{l}$ being the remaining life of the component in years.

$$
\begin{array}{r}
S=C_{\text {rep }} \times \frac{R_{l}}{n} \\
R_{l}=n-\left(y-\left(N_{\text {rep }} \times n\right)\right)
\end{array}
$$

The AOM and the AFC are determined as in [14] 


$$
\begin{array}{r}
A O M=\frac{C_{c} \times(1-\mu)}{n} \\
A F C=C_{f} \times f_{E} \times \sum_{t=1}^{365} E_{g e n}
\end{array}
$$

where $C_{c}$ is the capital cost, $\mu$ is the reliability of the component and $n$ is the lifetime of the component. $C_{f}$ is the fuel cost per litre in $\$ \mathrm{USD} / \mathrm{l}, f_{E}$ is the fuel consumption per unit energy $(1 / \mathrm{kWh}), E_{\text {gen }}$ is the backup fossil-fuel generator daily energy output $(\mathrm{kWh})$.

\subsubsection{Levelized Cost of Backup Electricity (LCoE)}

The cost of energy paid for the electricity produced and used in a year is computed using Eq. (4.12) where $E_{y e a r}$ is the electrical energy consumed in a year.

$$
L C o E=\frac{A C S}{E_{\text {year }}}
$$

\subsection{Results and Discussion}

A hybrid node is designed each for a household and a small enterprise. The results are discussed below in comparison to the baseline system of having a fossil-fuel backup generator.

\subsubsection{Technical and Economic Analysis}

The technical and economic results for the designed hybrid systems are as shown. From Table 4.1, the baseline system consists of the fossil-fuel backup generator as the main power source during power outage. The designed system is the hybrid system to be at a node of a swarm grid consisting of both a fossil-fuel backup generator and the PV system generator.

From Table 4.2, the designed hybrid systems are more cost effective than the baseline system by the end of their life time, as shown by lower values of the annualized costs of the systems. The levelized cost per unit of energy used is also lower for the designed system. The system costs are less due to reduced fuel consumption costs. The fuel costs reduced because of reduced usage hours of the fossil-fuel generators as more solar energy is used. 
Table 4.1 Technical analysis for the end user systems

\begin{tabular}{l|l|l|l|l|l}
\hline End users & $\begin{array}{l}\text { System } \\
\text { components }\end{array}$ & $\begin{array}{l}\text { Generator } \\
(\mathrm{kW})\end{array}$ & $\begin{array}{l}\text { Battery } \\
(\mathrm{Ah})\end{array}$ & $\begin{array}{l}\text { Inverter } \\
(\mathrm{VA})\end{array}$ & $\begin{array}{l}\text { Solar PV } \\
(\mathrm{Wp})\end{array}$ \\
\hline \multirow{2}{*}{ Household } & Baseline system & 1.0 & - & - & - \\
\cline { 2 - 6 } & Designed system & 1.0 & 150 & 850 & 300 \\
\hline \multirow{2}{*}{$\begin{array}{l}\text { Retail } \\
\text { shop }\end{array}$} & Baseline system & 1.0 & - & - & - \\
\cline { 2 - 6 } & Designed system & 1.0 & 200 & 500 & 400 \\
\hline
\end{tabular}

Table 4.2 Economic analysis for the end user systems

\begin{tabular}{l|l|l|l|l|l}
\hline End users & Economic parameters & AFC (\$ USD) & $\begin{array}{l}\text { LCoE } \\
\text { (\$ USD/ } \\
\mathrm{kWh})\end{array}$ & $\begin{array}{l}\text { ACS } \\
(\$ \text { USD })\end{array}$ & $\begin{array}{l}\text { ICS } \\
(\$ \text { USD })\end{array}$ \\
\hline \multirow{2}{*}{ Household } & Baseline system & 349.12 & 0.574 & 381.89 & 137.3 \\
\cline { 2 - 6 } & Designed system & 213.48 & 0.447 & 357.81 & 932.1 \\
\hline \multirow{2}{*}{ Retail shop } & Baseline system & 299.74 & 0.582 & 332.51 & 137.3 \\
\cline { 2 - 6 } & Designed system & 140.96 & 0.403 & 320.01 & 1069.6 \\
\hline
\end{tabular}

However, the Initial Cost of System (ICS) is higher for the designed hybrid systems as compared to the baseline systems. This could highly prevent the end users from integrating solar PV generator systems. Nevertheless, inclusive and flexible financial solutions could be used to make the systems more affordable as payment would only apply for the integrated solar PV system since the fossil-fuel generator as the baseline is already owned by the end users.

\subsubsection{Energy Analysis}

The production and consumption of different energy sources for the hybrid systems are analysed. Solar PV production and use in particular is also analysed. Excess energy potential is assessed and it is on that basis that recommendation for energy sharing in swarm grid is made.

From Fig. 4.5, fossil-fuel generator is still slightly used more throughout the year than the integrated solar energy for the household end user, however, its use has reduced to $51 \%$ with $49 \%$ integration of solar PV system as indicated in Fig. 4.6.

Figure 4.7 shows solar energy production is high at beginning and towards the end of the year. With the demand maintained constant, total excess solar energy of $27 \%$ is found for the household as illustrated in Fig. 4.8. The excess energy is 


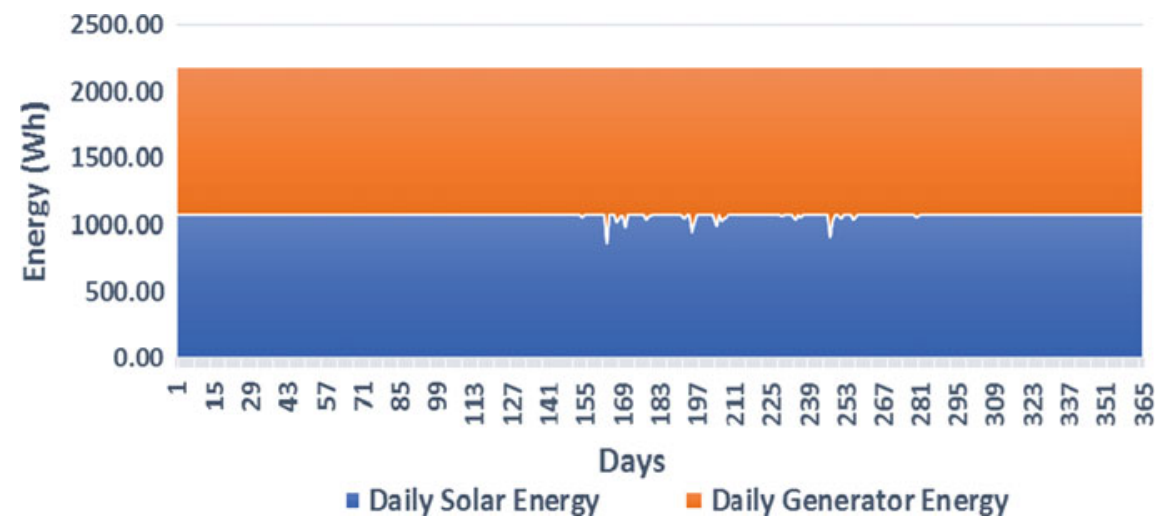

Fig. 4.5 Household end user energy consumption analysis

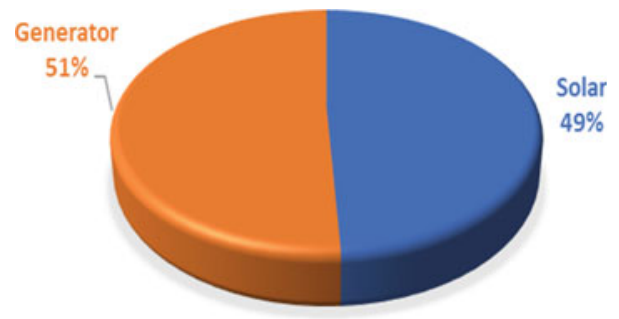

Fig. 4.6 Household energy mix

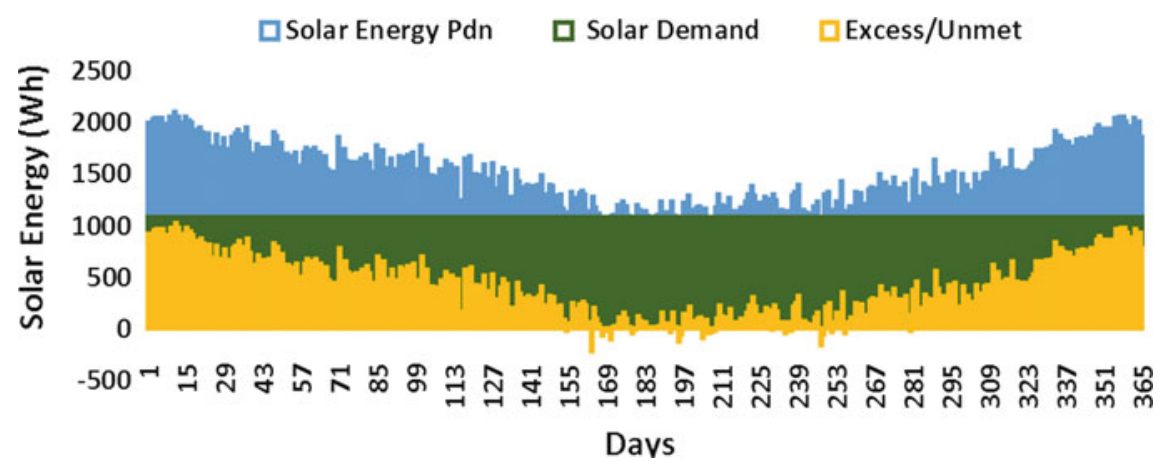

Fig. 4.7 Household end user solar energy production analysis 


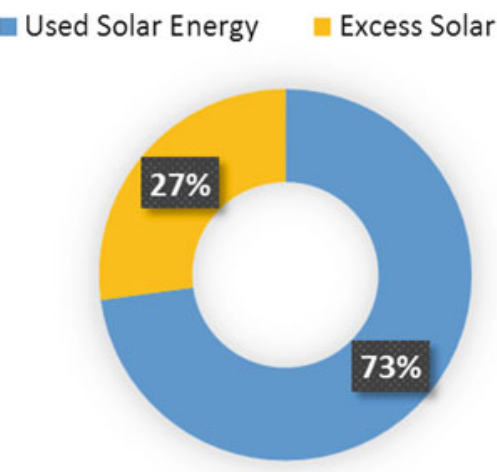

Fig. 4.8 Household end user ratio of excess solar energy

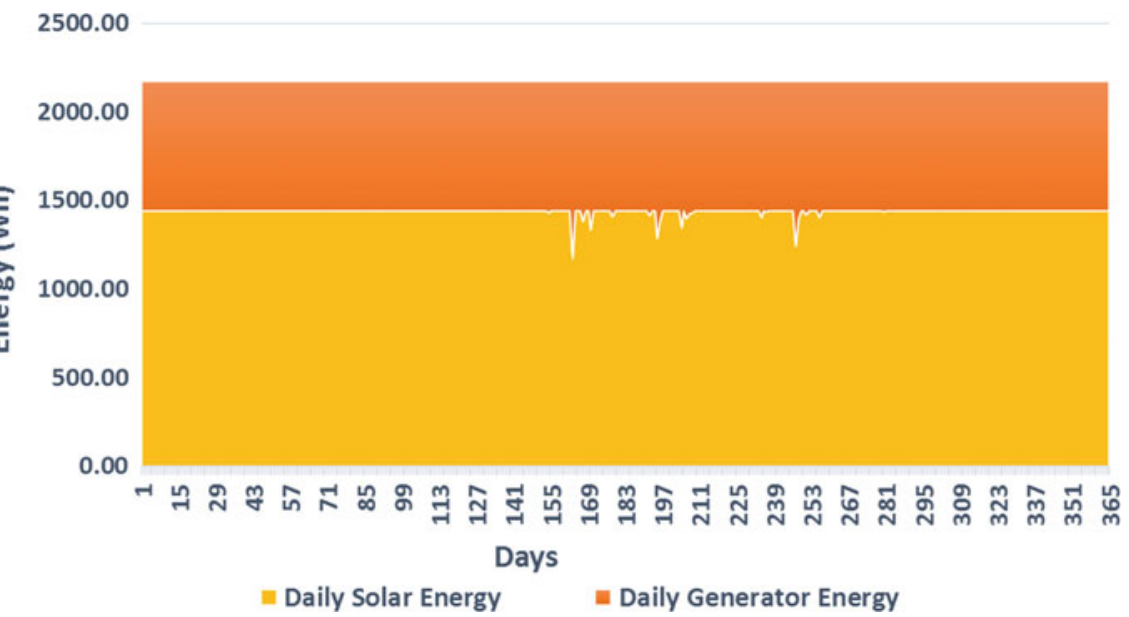

Fig. 4.9 Retail shop end user energy consumption analysis

generated on daily bases except in the middle of the year during rainy season when unmet energy is realized. The unmet energy is then supplied by the fossil-fuel generator as shown in Fig. 4.5.

For the retail shop enterprise, the integrated solar energy PV system becomes the main source throughout the year. Solar energy accounts for $66 \%$ of the daily use and fossil-fuel generator, 34\%. See Figs. 4.9 and 4.10.

Figure 4.11 for the retail shop end user shows solar energy production is high at beginning and towards the end of the year similar to the household end user as they are of the same geographical location. The fossil-fuel generator is used to meet the unmet solar energy in the rainy days especially in the middle of the year, see Figs. 4.9 and 4.11. Like for the household, the excess energy for the retail shop end user is found to be $28 \%$ (Fig. 4.12) and is also generated on daily bases. 


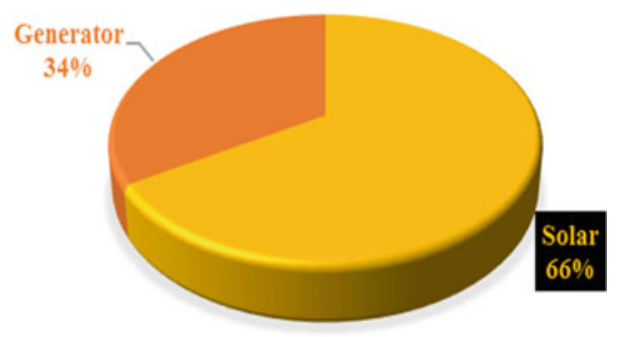

Fig. 4.10 Retail shop end user energy mix

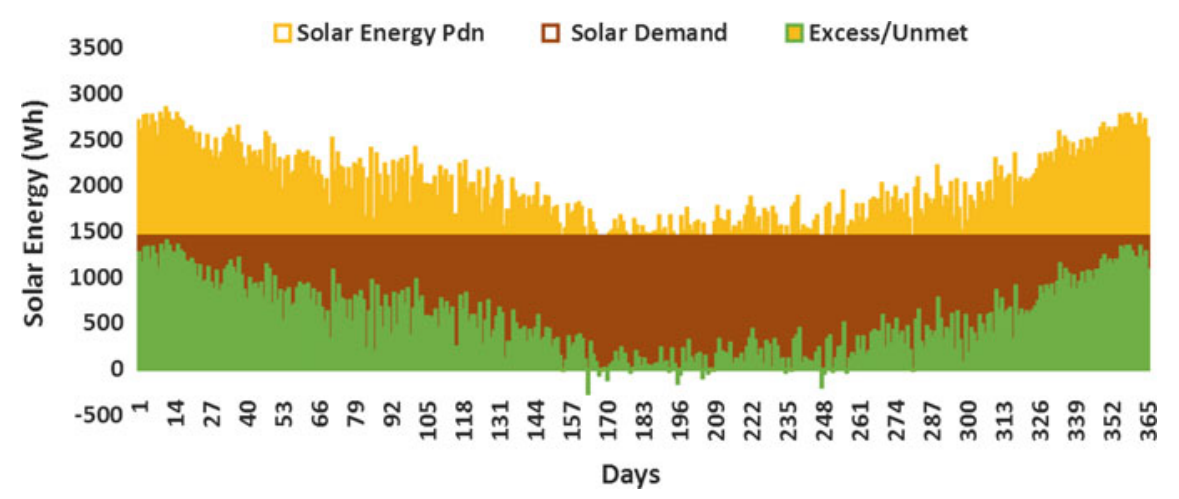

Fig. 4.11 Retail shop end user solar energy production analysis

Fig. 4.12 Retail shop end user ratio of excess solar energy

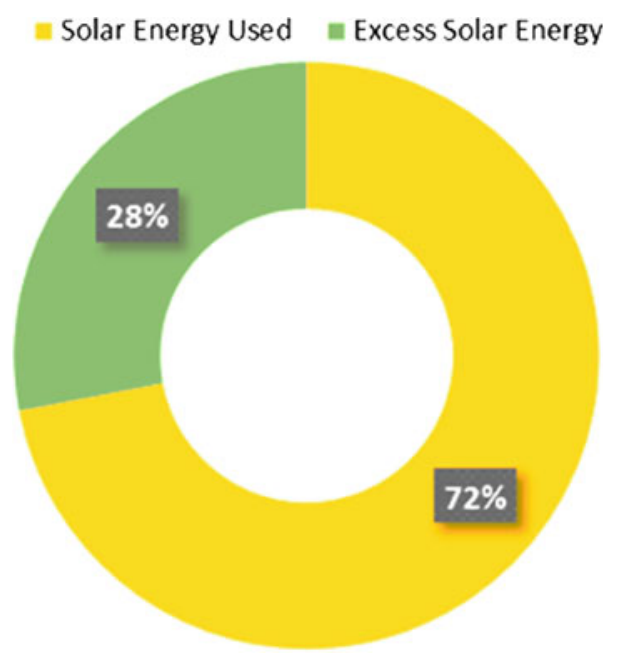


Table 4.3 Summary of results

\begin{tabular}{|c|c|c|c|c|c|c|}
\hline End users & Systems & $\begin{array}{l}\text { LCoE (\$ } \\
\text { USD/kWh) }\end{array}$ & $\begin{array}{l}\text { Reduction } \\
\text { in LCoE } \\
(\%)\end{array}$ & $\begin{array}{l}\text { AFC (\$ } \\
\text { USD) }\end{array}$ & $\begin{array}{l}\text { Reduction } \\
\text { in AFC } \\
(\%)\end{array}$ & $\begin{array}{l}\text { Excess } \\
\text { energy } \\
\text { (Solar) } \\
(\%)\end{array}$ \\
\hline \multirow[t]{3}{*}{ Household } & Baseline & 0.574 & - & 349.12 & & \\
\hline & $\begin{array}{l}\text { Designed } \\
\text { system }\end{array}$ & 0.447 & 22 & 213.48 & 39 & 27 \\
\hline & $\begin{array}{l}\text { Designed } \\
\text { system } \\
\text { (Swarm } \\
\text { grid) }\end{array}$ & 0.378 & 34 & & & \\
\hline \multirow{3}{*}{$\begin{array}{l}\text { Retail } \\
\text { shop }\end{array}$} & Baseline & 0.582 & - & 299.74 & & \\
\hline & $\begin{array}{l}\text { Designed } \\
\text { system }\end{array}$ & 0.403 & 31 & 140.96 & 53 & 28 \\
\hline & $\begin{array}{l}\text { Designed } \\
\text { system } \\
\text { (Swarm } \\
\text { grid) }\end{array}$ & 0.321 & 45 & & & \\
\hline
\end{tabular}

\subsubsection{Hybrid Swarm Grid Assessment}

The result of excess solar energy found in this study is similar to that of Kirchhoff, in which he found an excess energy of $30 \%$ of the potential solar energy production from a single solar home system [15], a typical case of Bangladesh. In a swarm grid the excess energy can be utilized instead of being wasted. Also, the excess energy can be utilized by connecting more loads when swarm grid infrastructure is still missing.

In a swarm grid where excess solar energy can be traded, Table 4.3 shows that the $\mathrm{LCoE}$ could reduce by $34 \%$ for the household and $45 \%$ for the retail shop end users operating as hybrid nodes in a hybrid swarm grid. In comparison to Bangladesh, the reduction in $\mathrm{LCoE}$ in this study is higher. This is a result of reduced use of fossil fuel generators while the systems in Bangladesh are purely single source solar home systems. The reduction in LCoE would enable the end users to access reliable and a more affordable electricity while supporting neighbors by trading excess energy in a swarm grid.

\subsection{Conclusion}

Power outages in SSA occur at a high rate, the situation is more alarming in Nigeria. This has resulted into high reliance on fossil-fuel backup generators for most households and small enterprises. However, these generators are noisy and their fuel is costly. This study looked at a stepwise strategy of integrating solar PV 
system with a backup household-based generator interconnected in a swarm grid for a potential benefit of fuel savings and environmental protection in line with SDG 7. The study focussed on the hybrid node of the swarm grid. From the result, a potential fuel savings and overall system cost reduction is found. Integrating solar, hence increases the share of renewable energy mix for the end users, generates excess energy that can be shared in a swarm grid by the grid participants. The overall result is that swarm grid would enable the energy consumers to become prosumers capable of sharing or trading energy produced among themselves. However, for a successful implementation of this concept in SSA, the social-cultural aspects of sharing electricity in a swarm grid should be investigated.

\section{References}

1. IEA and World Bank, Sustainable Energy For All Global Tracking Framework Progress Toward Sustainable Energy (2017)

2. IRENA, Solar PV in Africa: Costs and Markets (2016)

3. World Bank, Power outages in firms in a typical month (number). Enterprise Surveys (2016)

4. D.J. Ley, K. Gaines, A. Ghatikar, The Nigerian Energy Sector-An Overview with a Special Emphasis on Renewable Energy, Energy Efficiency and Rural Electrification (2014)

5. The Economist Intelligence Unit Limited, Enabling a More Productive Nigeria: Powering SMEs (2015)

6. S. Groh, D. Phillip, B. Edlefsen Lasch, H. Kirchhoff, Swarm electrification-investigating a paradigm sift through the building of microgrids bottom-up, in Decentralized Solutions for Developing Economies, eds. by S. Groh, J. Van der Straeten, B. Edlefsen Lasch, D. Gershenson, W. Leal Filho, D. Kammen. Springer Proceedings in Energy XXIV (2015), pp. 3-22

7. All On and Shell, Nigeria: Energy Needs Assessment and Value Chain Analysis (2016)

8. European Commission, Photovoltaic Geographical Information System (PVGIS) (2017) [Online]. http://re.jrc.ec.europa.eu/pvg_tools/en/tools.html\#HR. Accessed 04 June 2017

9. V. Anayochukwu Ani, Design of a reliable hybrid (PV/diesel) power system with energy storage in batteries for remote residential home. J. Energy 2016 (2016)

10. V. Anayochukwu Ani, Feasibility analysis and simulation of a stand-alone photovoltaic energy system for electricity generation and environmental sustainability — equivalent to 650VA fuel-powered generator - popularly known as 'I pass my neighbour'. Front. Energy Res. 3(Sept), 1-9 (2015)

11. O.S. Omogoye, A.B. Ogundare, I.O. Akanji, Development of a cost-effective solar/diesel independent power plant for a remote station. 2015 (2015)

12. P. Mohanty, T. Muneer, Smart design of stand-alone solar PV system for off grid electrification projects, in Mini-Grids for Rural Electrification of Developing Countries, eds. by S.C. Bhattacharyya, D. Palit. Green Energy and Technology (Springer, Cham, 2014), pp. 63-94

13. P.J. Boait, Technical aspects of mini-grids for rural electrification, in Mini-Grids for Rural Electrification of Developing Countries, eds. by S.C. Bhattacharyya, D. Palit. Green Energy and Technology (Springer, Cham, 2014), pp. 37-61

14. H. Suryoatmojo, A.A. Elbaset, F.A. Pamuji, D.C. Riawan, M. Abdillah, Optimal sizing and control strategy of hybrid PV-diesel-battery systems for isolated Island*. no. 1, 1-6

15. H. Kirchhoff, Microgrid Concepts with an Agent-Based Control Scheme in the Context of the Electrification in Off-Grid Areas (Technical University of Berlin, 2013) 
Open Access This chapter is licensed under the terms of the Creative Commons Attribution 4.0 International License (http://creativecommons.org/licenses/by/4.0/), which permits use, sharing, adaptation, distribution and reproduction in any medium or format, as long as you give appropriate credit to the original author(s) and the source, provide a link to the Creative Commons license and indicate if changes were made.

The images or other third party material in this chapter are included in the chapter's Creative Commons license, unless indicated otherwise in a credit line to the material. If material is not included in the chapter's Creative Commons license and your intended use is not permitted by statutory regulation or exceeds the permitted use, you will need to obtain permission directly from the copyright holder.

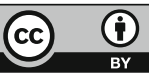

